\title{
Migration of mineral oil in elastomers
}

\author{
Tobias Förster ${ }^{1} \cdot$ Artur Blivernitz $^{1}$
}

Received: 25 September 2020 / Accepted: 3 February 2021 / Published online: 22 February 2021

(c) The Author(s) 2021

\begin{abstract}
This work describes a newly introduced experimental procedure to quantify the diffusion progress of mineral oils locally resolved in NBR. Diffusion of reference oils IRM 901, IRM 902 and IRM 903 in NBR with various acrylonitrile contents was investigated. Classical sorption experiments were performed as a basic characterization and compared to the newly introduced method. Here, elastomer specimens are only being dipped with the bottom in a relatively small reservoir of mineral oil. This provides a determination of locally resolved concentration profiles of mineral oils, and the calculation of diffusion coefficients. These diffusion coefficients follow the same trends like those determined via sorption experiments. Despite differences in the absolute numbers, activation energies of diffusion can be applied as a suitable measure for the compatibility of elastomers and fluids.
\end{abstract}

Keywords Diffusion · Mineral oil · NBR · Gas chromatography/mass spectrometry · Concentration profile

\section{Introduction}

During use, elastomers are frequently in close contact with surrounding media and can be exposed to relatively high temperatures. Certain components of these surrounding media, such as air, oil or fuels, might migrate into the elastomer bulk resulting in an overall volume change and a modification of material properties [1-7]. Depending on the dimensions of a component, an inhomogeneous penetration can result.

The diffusion rate strongly depends on the degree of interaction. Therefore, diffusion rates can give important evidence on the compatibility of elastomers with surrounding media. For sealing applications where mineral oils are involved, frequently acrylonitrile-butadiene rubber (NBR) is used as barrier material $[1,5,8-10]$. This results from the

Dr Michael Johlitz, Guest Editor of this Special Issue [New Challenges and Methods in Experimental Investigations and Modelling of Elastomers] confirms that where he was co-author of a research article in this Special Issue, he was not involved in either the peer review or the decision-making process of that particular article.

Tobias Förster

Tobias1Foerster@Bundeswehr.org

1 Wehrwissenschaftliches Institut Für Werk- Und Betriebsstoffe, Institutsweg 1, 85435 Erding, Germany fact that NBR normally exhibits a good resistance towards non-polar fluids due to its distinct polar nitrile groups. However, the compatibility between the elastomer and the surrounding medium is dominantly influenced by their chemical constitution. With regard to NBR especially the acrylonitrile (ACN) content determines the material's properties. An increasing ACN content leads not only to a better compatibility with non-polar media but also improves the aging stability as well as mechanical properties such as abrasion resistance, tensile strength and the hardness [1,11-13]. As mentioned, also the composition of the penetrating liquid has a significant influence on the occurring diffusion processes, which lead either to swelling or to shrinkage $[14,15]$. For hydrocarbon-based fluids in contact with NBR, it is well known that higher aromatic contents lead to higher uptakes by the elastomer and faster extraction of additives originating from enhanced polar interactions $[16,17]$. Therefore, the investigation of migration phenomena is always an important step for the evaluation of the compatibility between a certain elastomer and the corresponding fluid.

Since diffusion usually is a slow kinetically controlled process, concentration profiles of the penetrating liquid and elastomer additives develop in the bulk of the elastomer, which may lead to an inhomogeneous distribution of certain properties of the material with regard to specimen depth and ongoing sorption time. Hence, a detailed quantification of the occurring diffusion processes would contribute to a 
better understanding of swelling and shrinkage phenomena. However, results from experimental determination of spatially resolved concentration profiles of migrating fluids in elastomers are rarely found in literature.

Therefore, the emphasis of this work is laid on the investigation of local diffusion processes and their progression over time. For this purpose, first, a general characterization of the diffusion behaviors of the investigated elastomers was performed utilizing classical sorption experiments. In a second step, a new method was introduced allowing the monitoring of concentration profiles of both the penetrating fluid and the additives of the elastomer. The study is based on various sulfur-hardened NBR materials usable in service with various $\mathrm{ACN}$ contents including, e.g., fillers, plasticizers, antioxidants as well as residual curing agents. As test liquids, the three reference mineral oils IRM 901, IRM 902, and IRM 903, exhibiting different swelling potentials, were selected. The newly demonstrated diffusion experiments were carried out at different temperatures.

From the obtained data, individual concentration profiles of oils and plasticizer were determined and correlated with the hardness of the tested elastomer specimen. Transport characteristics especially diffusion coefficients were individually calculated. It was found that local changes of the mechanical property depend strongly on the concentration of the overall extractible matter in the examined area. The effects of simultaneous oil sorption and additive depletion were considered. Generally, this work provides a new simple to handle approach for spatial investigations of diffusion processes and their progression over time in polymers. This allows more precise predictions with respect to compatibility questions.

\section{Experimental}

\section{Materials}

All experiments were performed on three different, deployed in service, carbon black-filled acrylonitrile-butadiene rubbers E18, E28 and E39 with acrylonitrile contents of 18, 28 and 39\%, respectively. For reasons of comparability, the three sulfur-cured materials exhibit an identical composition except for the type of the acrylonitrile-butadiene copolymer as given in Table 1. All investigated elastomers were supplied by the Deutsches Institut für Kautschuktechnologie (DIK, Hannover).

The reference oils, ASTM oil 1 (IRM 901), IRM 902 and IRM 903 according to DIN ISO 1817 were supplied by Fuchs Europe Schmierstoffe GmbH and used without any further modification [18] (Table 2).
Table 1 Elastomer formulations

\begin{tabular}{llll}
\hline Component & \multicolumn{3}{l}{ Content/phr } \\
\cline { 2 - 4 } & E18 & E28 & E39 \\
\hline Perbunan 1846 & 100 & - & - \\
Perbunan 2845 & - & 100 & - \\
Perbunan 3945 & - & - & 100 \\
Bis(2-ethylhexyl) phthalate (DEHP) & 20 & & \\
N-(1,3-dimethylbutyl)-N'-phenyl-p-phenylene & 2 & & \\
$\quad$ diamine (6-PPD) & & & \\
Carbon black (N550) & 60 & & \\
Zinc oxide & 5 & & \\
Stearic acid & 1 & & \\
Sulfur & 2 & & \\
N-Cyclohexyl-2-benzothiazole sulfenamide (CBS) & 1.5 & & \\
TMTM-80 (80\% tetramethylthiuram monosulfide) & 0.5 & & \\
\hline
\end{tabular}

Table 2 Selected properties of reference oils

\begin{tabular}{llll}
\hline Property & IRM 901 & IRM 902 & IRM 903 \\
\hline $\begin{array}{l}\text { Kinematic viscosity } / 10^{-6} \\
\mathrm{~m}^{2} \mathrm{~s}^{-1 \mathrm{a}}\end{array}$ & $20\left(99{ }^{\circ} \mathrm{C}\right)$ & $20\left(99{ }^{\circ} \mathrm{C}\right)$ & $33\left(38^{\circ} \mathrm{C}\right)$ \\
$\begin{array}{l}\text { Flash point } /{ }^{\circ} \mathrm{C} \mathrm{min} \\
\text { a }\end{array}$ & 243 & 240 & 163 \\
Density at $15^{\circ} \mathrm{C} / \mathrm{g} \mathrm{cm}^{-3 a}$ & 0.886 & 0.933 & 0.921 \\
Paraffine content $/ \%$ & 31 & 49 & 43 \\
Naphthene content $/ \%$ & 64 & 39 & 43 \\
Aromatics content $/ \%$ & 5 & 12 & 14 \\
\hline
\end{tabular}

${ }^{\text {a }}$ Specified properties according to [18], not analytically determined

\section{Instrumentation}

Storage experiments at elevated temperatures were carried out in drying cabinets (type: T6120, Heraeus). An analytical balance AG 285, supplied by Mettler Toledo (accuracy $\pm 0.01 \mathrm{mg}$ ), was used for all weighing processes. Gas chromatography/mass spectrometry (GC/MS) analyses were performed on an Agilent 7890A gas chromatograph coupled to an Agilent 5975 MSD mass spectrometer equipped with a Double-Shot-Pyrolyzer PY-2020iD and a cold trap MicroJet Cryo-Trap MJT-1030E (Frontier Laboratories Ltd., Fukushima/Japan). The column was a $30 \mathrm{~m}$ Ultra Alloy 5 (0.25 mm inner diameter, $0.25 \mu \mathrm{m}$ film thickness). Helium was used as a carrier gas, while the mass spectrometer was operated in electron ionization mode (EI). The hardness of the specimens was determined with a digi test (Bareiss-Prüfgerätebau $\mathrm{GmbH}$ ) that is equipped with a respective micro Shore A module. 


\section{Gravimetric sorption experiments}

At first, thin sheets $\left(30 \times 10 \times 1 \mathrm{~mm}^{3}\right)$ of the three different elastomer types were extracted with acetone ( $>99 \%$, Sigma Aldrich) for 5 days using a soxhlet apparatus. After the complete extraction of the soluble additives DEHP, 6-PPD, stearic acid as well as residual CBS and TMTM-80, the samples were left out in an open air for 2 days, until acetone was completely desorbed. The dried specimens were then stored in $60 \mathrm{~mL}$ screw-tight glass vessels each containing the corresponding reference oil (all elastomer types were stored in the three different oils). After a certain period of time, the samples were taken out and cleaned with petroleum ether using a paper tissue. Finally, the mass of the dry specimens was determined by weighing, before the elastomer sheets were placed back into the immersion liquid. This procedure was repeated from time to time for approx. 3 months. The experiments were performed at temperatures of $60^{\circ} \mathrm{C}, 80^{\circ} \mathrm{C}$ $\left(70{ }^{\circ} \mathrm{C}\right), 100{ }^{\circ} \mathrm{C}$ and $120^{\circ} \mathrm{C}$. Sorption curves (solid lines) and averaged diffusion coefficients $D$ were calculated by iterative fitting of the experimental data according to Eq. (1) considering the first 11 elements of the infinite series. The equation is applicable to one-dimensional diffusion in a plane sheet according to Fick's second law [19].

$\frac{m_{t}-m_{0}}{m_{\infty}-m_{0}}=\frac{M_{t}}{M_{\infty}}=1-\frac{8}{\pi^{2}} \sum_{n=0}^{\infty}\left(\frac{1}{(2 n+1)^{2}}\right) \mathrm{e}^{\frac{-(2 n+1)^{2} \pi D t}{h^{2}}}$

$m_{t}$ is the elastomer mass at time $t$, while $m_{0}$ corresponds the initial mass of the extracted sample. $h$ is the specimen thickness (here approx. $1 \mathrm{~mm}$ ) and $n$ the running index. $m_{\infty}$ is the elastomer sheet mass at saturation.

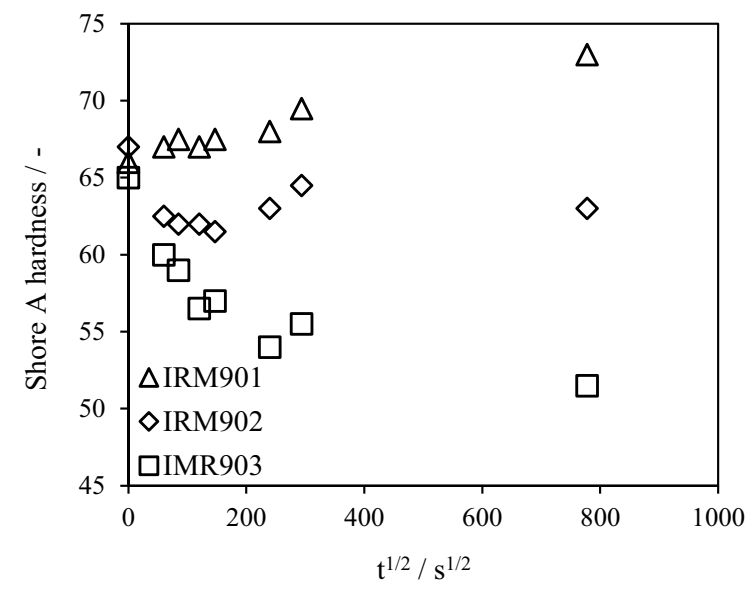

\section{Spatial resolved migration experiments}

First, $100 \mathrm{~mL}$ volumetric flasks were filled with approx. $250 \mu \mathrm{L}$ of IRM 903 or IRM 902 to generate a thin layer (approx. $0.5 \mathrm{~mm}$ ) of the respective oil on the bottom of the flask. Elastomer strips $\left(90 \times 5 \times 2 \mathrm{~mm}^{3}\right)$ were then placed upright in the flask to ensure that only the bottom tip of the specimens was in contact with the test fluid. This procedure allows the assumption of a one-dimensional oil diffusion in the elastomer samples. The experiments were performed at $60{ }^{\circ} \mathrm{C}, 80^{\circ} \mathrm{C}, 100^{\circ} \mathrm{C}$ and $120^{\circ} \mathrm{C}$ for $24 \mathrm{~h}$. After storage, the specimens were taken out and cleaned with petroleum ether to remove oil from the surface. The hardness was then measured along the lower part (first $20 \mathrm{~mm}$ ) of the specimens at a distance of $1 \mathrm{~mm}$ resulting in 19 data points as the first point was determined at a distance of $2 \mathrm{~mm}$ from the bottom edge. Afterwards, the lower part of the strips was cut into 20 samples of approx. $1 \mathrm{~mm}$ length using a sharp scalpel. The exact thickness of the specimens was determined with a micrometer screw gauge. For thermal desorption GC/MS analyses, pieces of approx. $0.3-0.8 \mathrm{mg}$ were cut out from the middle part of the previously prepared $1 \mathrm{~mm}$ thick samples and placed into the respective stainless-steel sample cups. The volatile matter was thermally desorbed at $300{ }^{\circ} \mathrm{C}$ for $5 \mathrm{~min}$ and condensed in a cold trap. Subsequently, a gas chromatographic separation was performed.

The quantification of the mineral oils, the anti-aging agent and the plasticizer was performed by external calibration using linear regression. For this purpose, standard solutions were prepared by dilution of the respective mineral oil, 6-PPD and DEHP in acetone. To cover the required calibration range, appropriate quantities of the standard solutions were pipetted into the stainless-steel sample cups and the exact mass was determined by weighing. These calibration

Fig. 1 Influence of mineral oils on Shore A hardness (left) and the volume change (right) of E18 ( $x$ axis is displayed in $t^{1 / 2}$ for reasons of comparability)

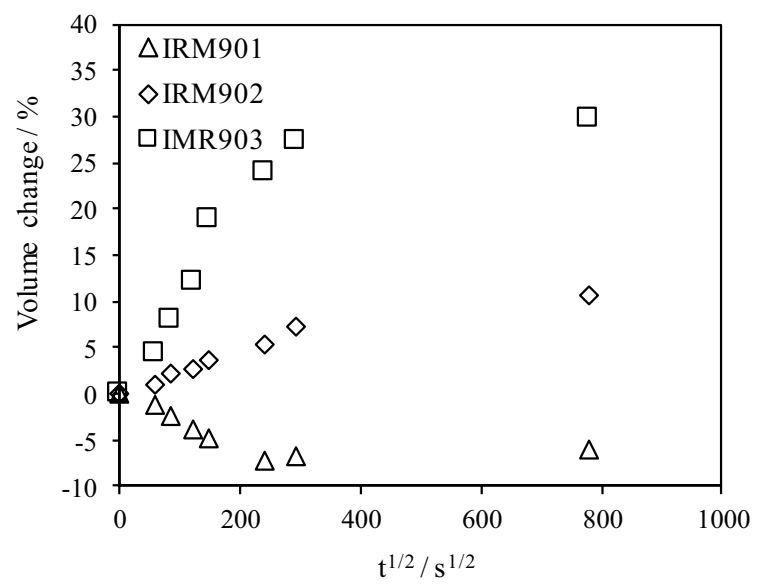


specimens were then analyzed analog to the elastomer samples as described before.

\section{Results and discussion}

\section{Gravimetric sorption experiments}

Classical compatibility investigations include the storage of elastomer specimens in a liquid for several days up to several weeks at elevated temperatures. Figure 1 shows the effect on the elastomer hardness and volume after storage in the three mineral oils IRM 901, 902 and 903 at $100{ }^{\circ} \mathrm{C}$ for up to 7 days exemplarily for non-pre-treated E18. As expectable, a shrinkage occurs after storage in IRM 901, i.e., a net loss of soluble matter. Medium swelling in IRM 902 and pronounced swelling in IRM 903 can be observed. Consequently, Shore A hardness is affected by the change in material composition. Hence, the material becomes softer after storage in IRM 903. On the other hand, a volume reduction triggered by storage in IRM 901 corresponds to an increase in hardness, most likely caused by an extraction of the plasticizer. Classical swelling experiments with ready to use elastomers, therefore, only give information on overall changes of the material. Without further chemical analyses, no information on the detailed material composition is derivable.

One possibility to focus on the uptake of mineral oils is the chemical extraction of elastomer additives prior to sorption experiments. This procedure allows an understanding of the overall uptake characteristics of materials by gravimetrical determination. Figures 2,3,4 show sorption characteristics of the three tested elastomers for the storage in IRM 901,902 and 903 at temperatures in ranging from $60^{\circ} \mathrm{C}$ to $120^{\circ} \mathrm{C}$ and storage durations up to approx. 3 months.

It is obvious, that maximum uptakes of oil, corresponding to the horizontal part in each curve, increase with temperature. This is explained by a higher mobility of the polymer chains creating voids for diffusing fluids. Additionally, one can learn that diffusion coefficients, that are proportional to
Fig. 2 Relative mass change of elastomers E18, E28 und E39 after storage in IRM 901 in dependence on the storage duration for $60^{\circ} \mathrm{C}, 80^{\circ} \mathrm{C}$, $100{ }^{\circ} \mathrm{C}$ and $120^{\circ} \mathrm{C}$ (solid lines correspond to sorption curves and were calculated by iterative fitting of the experimental data according to Eq. (1))
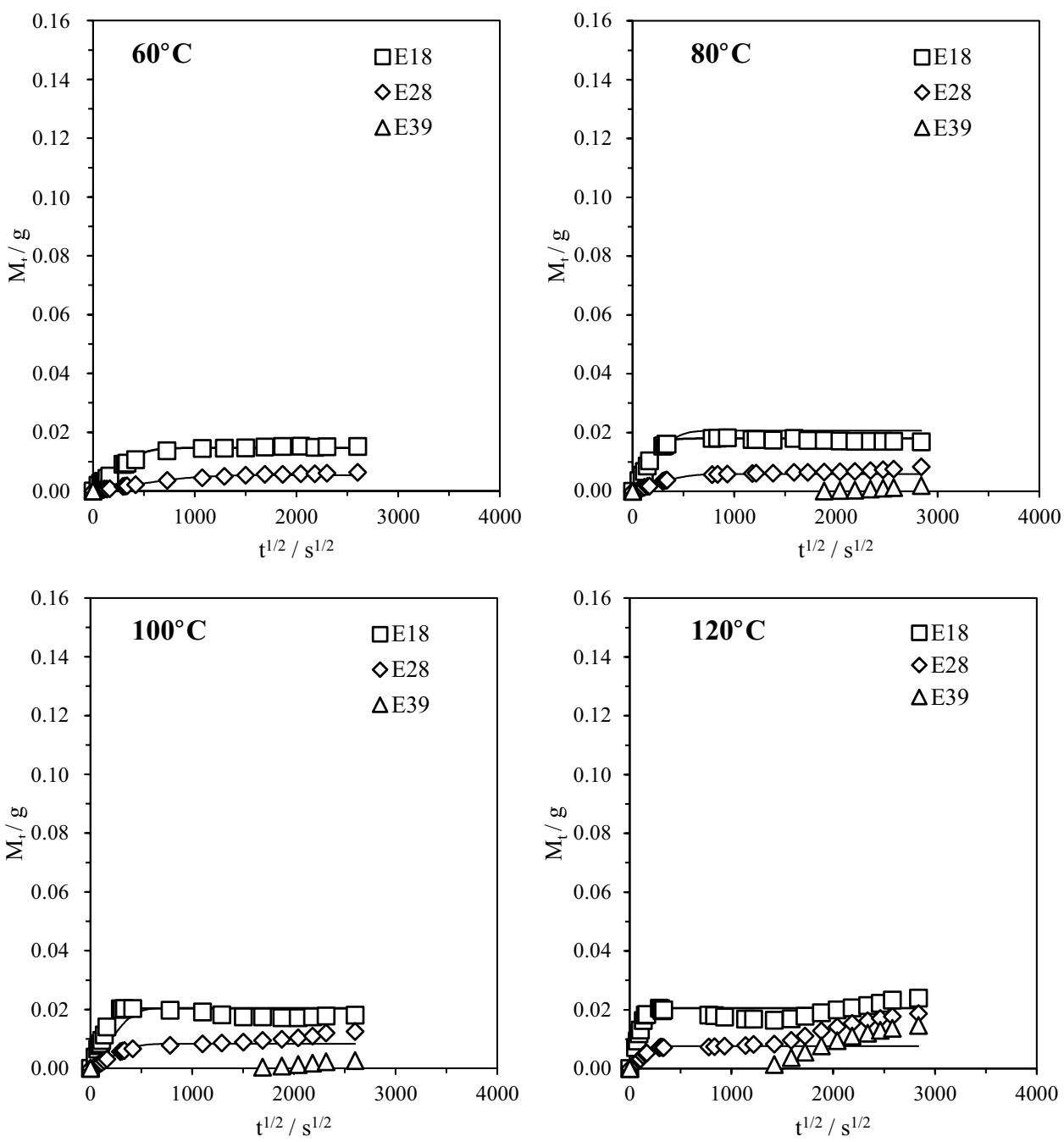
Fig. 3 Relative mass change of elastomers E18, E28 und E39 after storage in IRM 902 in dependence on the storage duration for $60^{\circ} \mathrm{C}, 80^{\circ} \mathrm{C}$, $100{ }^{\circ} \mathrm{C}$ and $120^{\circ} \mathrm{C}$ (solid lines correspond to sorption curves and were calculated by iterative fitting of the experimental data according to Eq. (1))
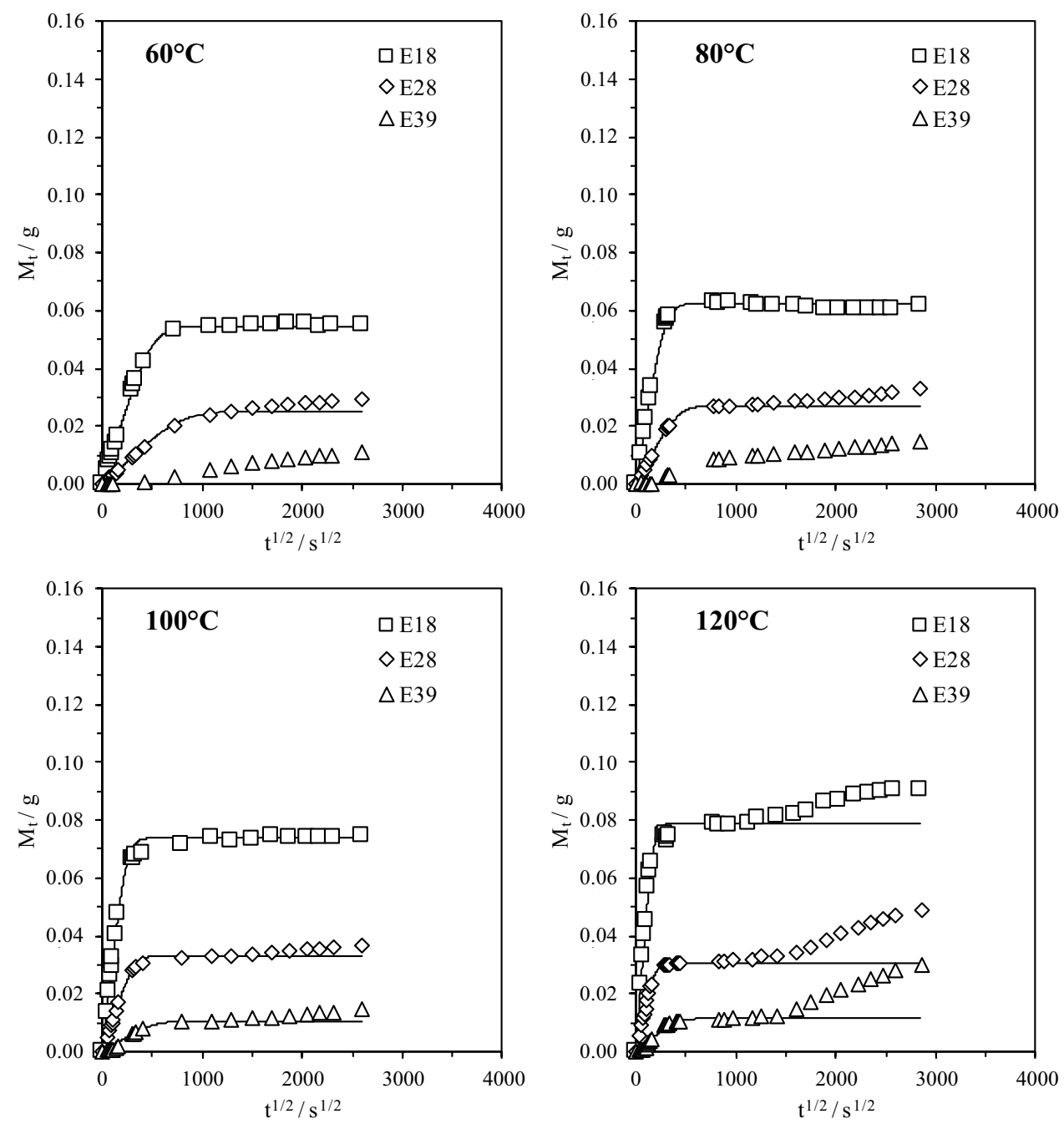

the slope in the beginning of each curve, follow the same trend. This is also reflected in a reduction of the required time until equilibrium state due to faster diffusion. From the diagram shapes, it is concluded that the mass transport is nearly perfectly described by Fickian laws. Trends are equal for all investigated mineral oils, but in the case of IRM 901, slight deviations from the ideal Fickian diffusion behavior are observed. This can be explained by analytical errors and especially by the fact that diffusion of IRM 901 in E39 is significantly slower because the resistance of this elastomer against IRM 901 is very good. Therefore, for this combination, no diffusion coefficients could be determined from the data. Sometimes a second increase in mass is observed, especially at high temperatures. The reason for this is assumed to be found in a partial oxidation of the mineral oils leading to a change of the fluid's polarity, which was proven by infrared spectroscopy. This additional oil uptake is relatively slow as the extent of oxidation is low. It is expected that this effect could be excluded by storage under inert gas. Furthermore, slow overlaying processes, which are not considered by prevalent models, cannot be excluded. Hence, deviations of the equilibrium uptake after long storage durations were not taken into account for further interpretations.

The maximum mineral oil uptake at equilibrium correlates not only with the acrylonitrile content but also with the swelling potential of the mineral oil. An explanation for this is found in the elastomer's polarity, which strongly depends on the acrylonitrile content. Non-polar mineral oils show more intense interactions with less polar polymers.

The swelling potential of the tested oils increases in the order IRM $901<$ IRM $902<$ IRM 903, which results from IRM 903's highest aromatic content and its relatively high amount of short molecules with low sterical demand. Additionally, IRM 903 shows the lowest viscosity and the lowest boiling range. This is reflected in the amount of adsorbed mineral oil which correlates with the solubility of mineral oils in elastomers. For example, E18 adsorbs up to approx. $110 \mathrm{mg}$, whereas E28 only takes up approx. $70 \mathrm{mg}$ and E39 approx. $20 \mathrm{mg}$ of IRM 903 at $100{ }^{\circ} \mathrm{C}$. 
Fig. 4 Relative mass change of elastomers E18, E28 und E39 after storage in IRM 903 in dependence on the storage duration for $60{ }^{\circ} \mathrm{C}, 70{ }^{\circ} \mathrm{C}$, $100{ }^{\circ} \mathrm{C}$ and $120^{\circ} \mathrm{C}$ (solid lines correspond to sorption curves and were calculated by iterative fitting of the experimental data according to Eq. (1))
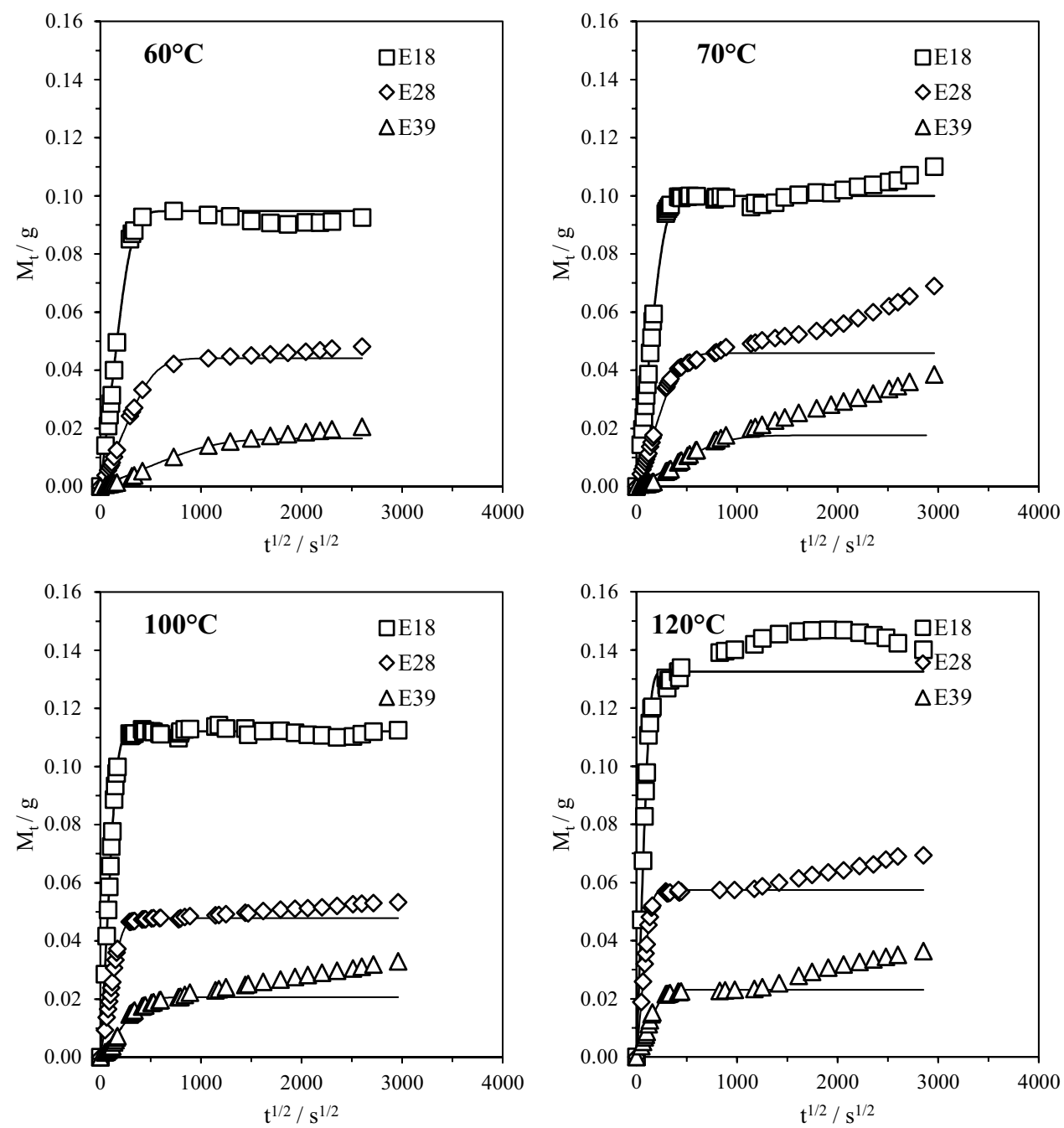

Table 3 Diffusion coefficients determined via sorption experiments for IRM 901, 902 and 903 in E18, E28 and E39 in the temperature range from $60{ }^{\circ} \mathrm{C}$ to $120^{\circ} \mathrm{C}$

\begin{tabular}{|c|c|c|c|c|}
\hline \multirow[t]{2}{*}{ Elastomer } & \multicolumn{4}{|c|}{$\mathrm{D}_{\mathrm{S}} / 10^{-8} \mathrm{~cm}^{2} \mathrm{~s}^{-1}$} \\
\hline & $120^{\circ} \mathrm{C}$ & $100^{\circ} \mathrm{C}$ & $80^{\circ} \mathrm{C}$ & $60^{\circ} \mathrm{C}$ \\
\hline \multicolumn{5}{|l|}{ IRM 901} \\
\hline E18 & 7.3 & 3.7 & 2.0 & 0.7 \\
\hline E28 & 3.1 & 1.0 & 0.6 & 0.2 \\
\hline E39 & n. d & n. d & n. d & n. d \\
\hline \multicolumn{5}{|l|}{ IRM 902} \\
\hline E18 & 5.8 & 3.1 & 2.0 & 0.6 \\
\hline E28 & 5.0 & 1.6 & 1.0 & 0.3 \\
\hline E39 & 1.2 & 0.6 & n. d & n. d \\
\hline \multirow[t]{2}{*}{ Elastomer } & \multicolumn{4}{|c|}{$\mathrm{D}_{\mathrm{S}} / 10^{-8} \mathrm{~cm}^{2} \mathrm{~s}^{-1}$} \\
\hline & $120^{\circ} \mathrm{C}$ & $100{ }^{\circ} \mathrm{C}$ & $70^{\circ} \mathrm{C}$ & $60^{\circ} \mathrm{C}$ \\
\hline \multicolumn{5}{|l|}{ IRM 903} \\
\hline E18 & 11.3 & 6.6 & 2.4 & 1.7 \\
\hline E28 & 9.4 & 3.8 & 1.0 & 0.7 \\
\hline E39 & 2.8 & 1.0 & 0.2 & 0.1 \\
\hline
\end{tabular}



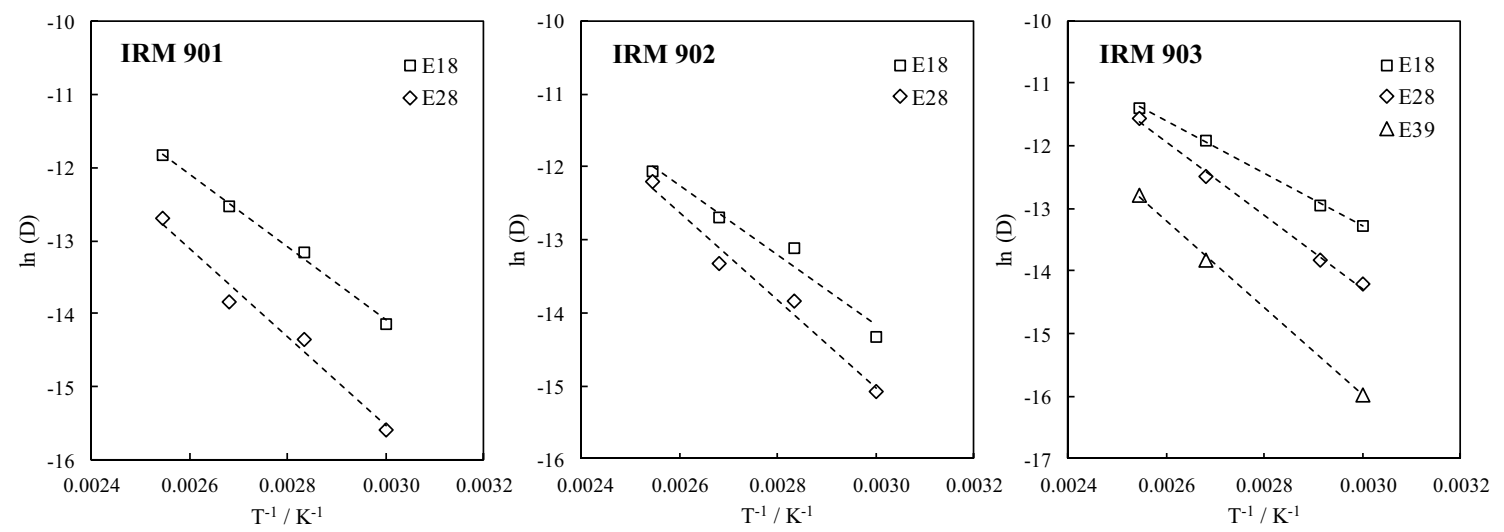

Fig. 5 Arrhenius plots for sorption experiments of mineral oils IRM 901, 902 and 903 in elastomers E18, E28 and E39

Diffusion defines the kinetics of mineral oil uptake in the beginning phase of storage. Iteration of Eq. (1) allows the determination of diffusion coefficients for sorption $\left(D_{\mathrm{S}}\right)$ experiments. Table 3 gives an overview of determined values. Diffusion coefficients are calculated higher when a more pronounced and faster mineral oil uptake is found. For example, the diffusion coefficient of IRM 903 decreases from $11.3 \times 10^{-8} \mathrm{~cm}^{2} \mathrm{~s}^{-1}$ in E18 via $9.4 \times 10^{-8} \mathrm{~cm}^{2} \mathrm{~s}^{-1}$ in E28 to $2.8 \times 10^{-8} \mathrm{~cm}^{2} \mathrm{~s}^{-1}$ in $\mathrm{E} 39$ at $120{ }^{\circ} \mathrm{C}$. Within one elastomer-oil system, Arrhenius-like temperature behavior can be observed (s. Fig. 5).

IRM 903 exhibits the highest diffusion coefficients for any elastomer-oil combination followed by IRM 902 and IRM 901. This corresponds to the swelling potential, which subsumes the parameters aromatic fraction, molecule size, viscosity and boiling range. IRM 901 shows the lowest diffusion coefficients for all elastomers. Exceptions are experiments of E18 in IRM901 at temperatures of $120^{\circ} \mathrm{C}, 100{ }^{\circ} \mathrm{C}$ and $60{ }^{\circ} \mathrm{C}$ which show marginally higher values than experiments of E18 in IRM 902. After storage of E18 in IRM 901 at $100{ }^{\circ} \mathrm{C}$ and $120^{\circ} \mathrm{C}$, discrepancies between experimental and calculated curve progression are observed. The reason for this cannot be derived from the present data finally. However, this phenomenon is known in literature for diffusion of dichloromethane in Santropen [20]. Changes in the polymer chain morphology are described as possible reasons for this observation, which are caused by the uptake of the diffusing fluid. Nevertheless, these discrepancies are considered acceptable, as minor inaccuracies in the calculations occur when values are comparably low. Determined diffusion coefficients are typical for mineral oils diffusing in relatively polar polymers. According to Bellili et al. a diffusion coefficient of $15.0 \times 10^{-8} \mathrm{~cm}^{2} \mathrm{~s}^{-1}$ was published for IRM 903 in ethylene vinyl acetate [19].

The temperature dependence of the diffusion process is described by the activation energy, which is derived from the corresponding Arrhenius plot (s. Fig. 5). As no diffusion
Table 4 Activation energies determined via sorption experiments for IRM 901, 902 and 903 in E18, E28 and E39 in the temperature range from $60{ }^{\circ} \mathrm{C}$ to $120{ }^{\circ} \mathrm{C}$

\begin{tabular}{llll}
\hline Elastomer & $\mathrm{E}_{\mathrm{A}} / \mathrm{kJ} / \mathrm{mol}$ & & \\
\cline { 2 - 4 } & IRM 903 & IRM 902 & IMR 901 \\
\hline E18 & 34.7 & 39.6 & 41.1 \\
E28 & 48.1 & 49.6 & 49.9 \\
E39 & 56.8 & n. d & n. d \\
\hline
\end{tabular}

coefficients could be calculated for IRM 901 and IRM 902 diffusing in E39, no activation energies could be derived (s. Table 4).

Activation energies of diffusion in sorption experiments seem to increase in the order IRM 903 via IRM 902 to IRM 901 independent of the elastomer type. Thus, a temperature increase results in a stronger acceleration of diffusion in IRM 901 compared to storage in IRM 902 or IRM 903. Elastomers with higher acrylonitrile content show higher activation energies. In literature polymers with higher rigidity exhibit higher activation energies [21]. In addition, macromolecules of PAN are described as relatively rigid due to repulsive effects of their nitrile groups [22]. Therefore, it is assumed, that with increasing acrylonitrile content NBR becomes more rigid. An increase in temperature, leads to a widening of the polymer network resulting in an accelerated diffusion. The temperature effect is more pronounced in this case compared to materials, which already take up relative high amounts of mineral oil at lower temperatures. Therefore, the activation energy of diffusion is proposed as a criterion for compatibility.

In comparison to literature, the determined activation energies in the range from 34.7 to $56.8 \mathrm{~kJ} \mathrm{~mol}^{-1}$ are relatively high for diffusion processes. Mathai et al. published activation energies for the solvents toluene and p-xylene in NBR of 2.2 and $4.3 \mathrm{~kJ} \mathrm{~mol}^{-1}$, respectively [23]. The reduced 
mobility of the mineral oils, caused by relatively high molecular masses, might explain the comparably high activation energies in this work [24].

\section{Spatial resolved migration experiments}

Sorption experiments offer valuable general information on the compatibility of mineral oils with elastomers. However,

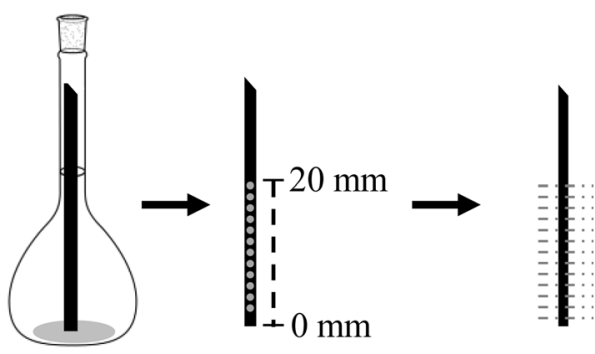

no spatially resolved conclusions can be drawn. When larger elastomer components are in contact with non-polar liquids an uptake of these substances occurs heterogeneously. Due to diffusion processes, a homogeneous distribution of adsorbed liquids cannot occur instantaneously. In consequence, material properties are affected in dependence of the extent of overall liquid uptake and on the penetration depth of the surrounding liquid. In order to understand and evaluate processes in larger elastomer parts, local resolution of the concentration is necessary.

Therefore, the experimental setup was optimized to allow diffusion of mineral oil in only one direction. Specimens are only dipping in a limited amount of oil during the storage procedure. After storage, thin slices of the original specimen are cut with a knife followed by pyrolysis GC/MS to determine the composition of each slice (s. Fig. 6).

This procedure allows for the generation of concentration profiles of adsorbed mineral oil. The shape of these profiles is typical for fluids diffusing in a solid with a constant

Fig. 6 Experimental setup during migration experiments

Fig. 7 Concentration profiles of IRM 903 in elastomers in dependence on the penetration depth after $24 \mathrm{~h}$ at temperatures between $60{ }^{\circ} \mathrm{C}$ and $120{ }^{\circ} \mathrm{C}$ (dashed lines correspond to sorption curves and were calculated by iterative fitting of the experimental data according to Eq. (2))
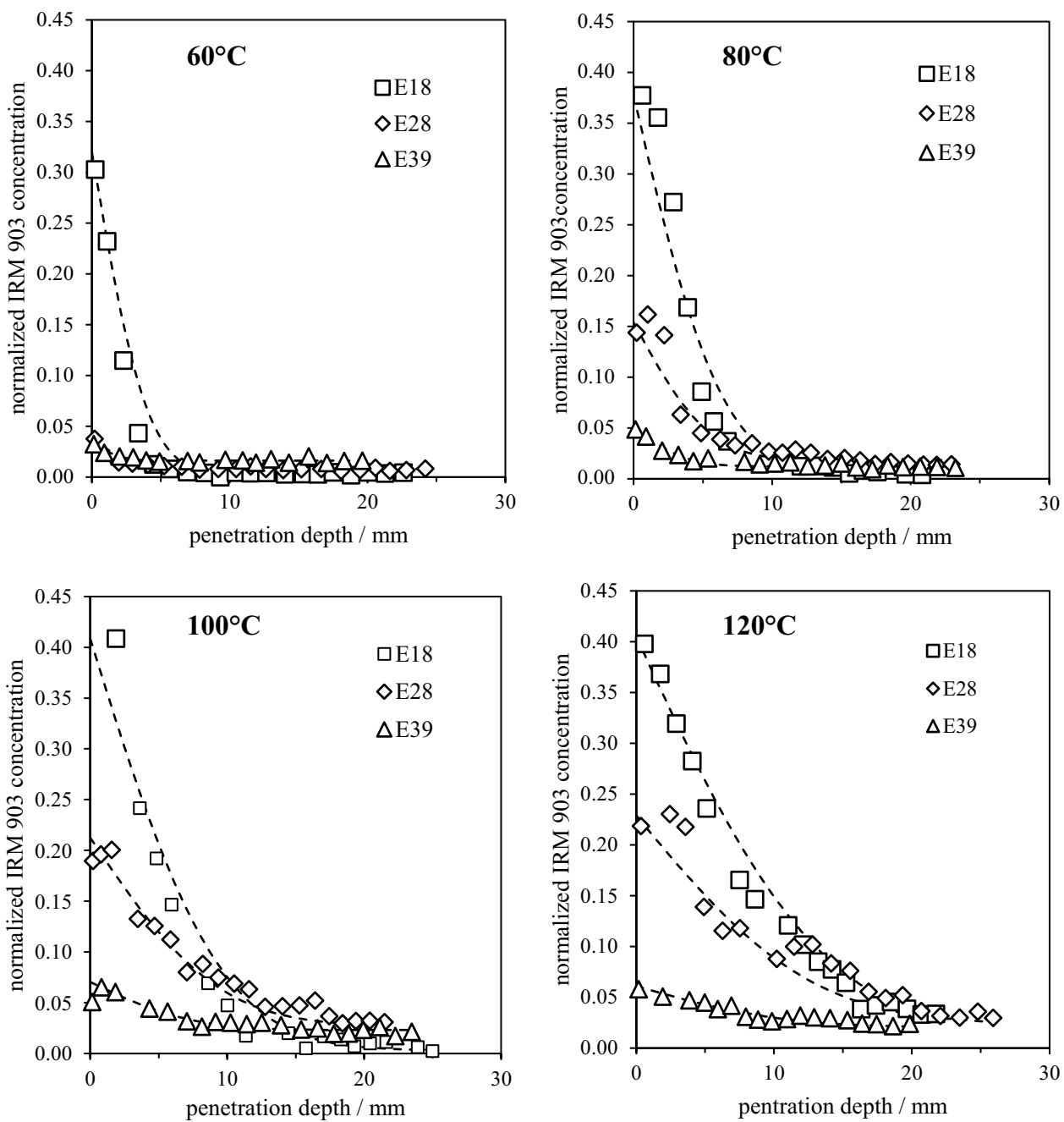
Fig. 8 Concentration profiles of IRM 902 in elastomers in dependence on the penetration depth after $24 \mathrm{~h}$ at temperatures between $60^{\circ} \mathrm{C}$ and $120^{\circ} \mathrm{C}$ (dashed lines correspond to sorption curves and were calculated by iterative fitting of the experimental data according to Eq. (2))
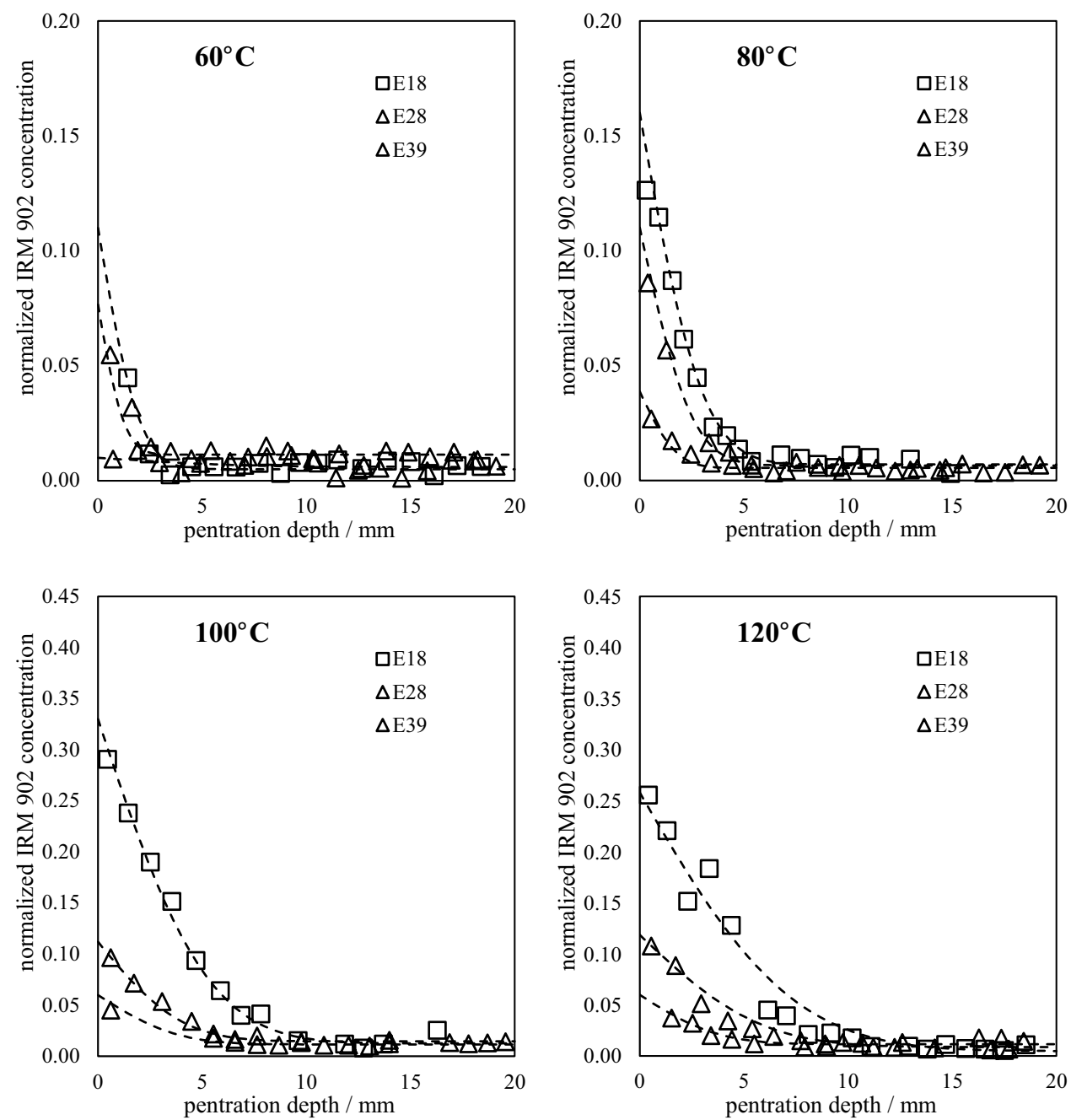

surface concentration. Thus, diffusion can be described mathematically with Eq. (2): [25]

$c(x, t)=c_{\mathrm{s}}-\left(c_{\mathrm{s}}-c_{0}\right) \operatorname{erf}\left(\frac{x}{2 \sqrt{D t}}\right)$

Figure 7 shows locally resolved mineral oil concentrations in the elastomers E18, E28 and E39 after storage in IRM 903 at temperatures between $60{ }^{\circ} \mathrm{C}$ and $120{ }^{\circ} \mathrm{C}$ for $24 \mathrm{~h}$. Relative mineral oil concentrations were determined by pyrolysis-GC/MS and are normalized to solid elastomer components (polymer and carbon black). Figure 8 comprises concentration profiles of IRM 902 under equal storage conditions. At penetration depths of 0 (end of specimen dipping in mineral oil), equilibrium concentrations are reached after short storage times. These equilibrium concentrations agree very good with values determined during the overall uptake samples (s. Figs. 1,2,3,4). All trends derived from the basic characterization experiments are confirmed and a clear correlation to the compatibility is obvious. For every tested mineral oil/temperature combination, the most noticeable uptake of oil is reached with E18; whereas, E39 experiences the lowest degree of mineral oil uptake. One can also see that IRM 903 is favorably adsorbed compared to IRM 902 under the same storage conditions. Finally, a temperature dependence is observable for all elastomer types, i.e., increased uptake at higher temperatures. Experiments with IRM 901 were not further considered as no significant additional information gain was expected with regard to the basic characterization experiments.

Not only the maximum uptake of mineral oil, but also the penetration depth follows the trend of the mineral oil's swelling potential. IRM 903 shows further advanced diffusion progress than IRM 902 for all tested temperatures and elastomers. After 24 h, IRM 903 reached a maximal penetration depth of approximately $20 \mathrm{~mm}$ in E18 at $120{ }^{\circ} \mathrm{C}$, whereas only approx. $10 \mathrm{~mm}$ are reached in E39. The maximal penetration depth here is defined as a significant increase of adsorbed mineral oil in comparison to the plateau concentration.

With increasing penetration depth, the amount of adsorbed oil generally declines. Against theoretical 


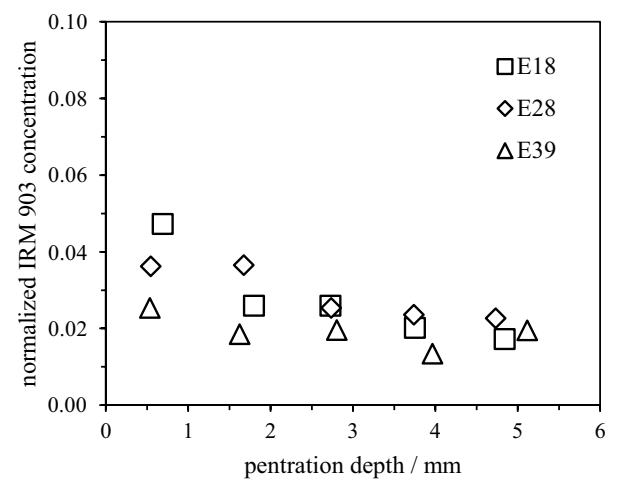

Fig. 9 Normalized concentration of IRM 903 in elastomers E18, E28 and E39 in dependence on the penetration depth after $24 \mathrm{~h}$ in the headspace at $100^{\circ} \mathrm{C}$

considerations, concentrations do not drop to 0 , but a constant minimum value (plateau) is reached. This can be explained by oil vapor adsorption via the gas phase during storage. Experiments with a specimen not dipped in the liquid but hung above without any direct contact confirm this assumption. Fig. 9 shows oil concentrations after storage in the headspace of IRM 903 at $100{ }^{\circ} \mathrm{C}$ for $24 \mathrm{~h}$.

The amount of IRM 903 adsorbed via the gas phase is in very good agreement with plateau concentrations reached after the dipping storage procedure. Although a minimal dependence on the distance to the liquid reservoir can be seen, it is assumed that a certain amount of mineral oil is adsorbed via gas phase. This is considered to be specific for every mineral oil-elastomer-temperature combination.

Iteration of Eq. (2) allows the determination of diffusion coefficients for the spatial resolved migration experiments (for results s. Table 5). Within one elastomer type, diffusion coefficients increase with higher temperatures for both investigated mineral oils.

Experimental results prove that a faster and more pronounced uptake of mineral oil is seen for IRM 903 compared to IRM 902 under equal experimental conditions. This is reflected in the determined diffusion coefficients.

Diffusion coefficients determined from the migration experiments are about two orders of magnitude higher than values derived from the sorption experiments (s. Tables 3 and 5). Although the oil amount during storage in the sorption setup is clearly higher and the oil can access specimens from all sides, uptake coefficients are lower. This can be explained by the normalization to the whole specimen weight. In case of the migration experiments, very small elastomer slices are analyzed focussing on the local resolution. That means diffusion coefficients are mathematically based on different elastomer masses, as in the case of sorption experiments, where a higher fraction of uninvolved elastomer is considered for the calculation. The sample geometry also has an influence on the permeation process. In sorption experiments, the maximum diffusion path is half of the sample thickness. Whereas during dipping it is significantly larger, namely the whole specimen length. In consequence, concentration gradients, as the driving force for diffusion, decrease faster during sorption experiments. This might explain higher diffusion coefficients for the migration experiments. The maximum solubility of mineral oils is reached relatively fast in the sorption experiments, corresponding to a decrease of the diffusion velocity. This poses a further aspect for lower diffusion coefficients during the sorption experiments. Another factor that should not be neglected is that elastomers are extracted prior to sorption experiments. The plasticizer seems to have an accelerating effect on the diffusion of mineral oil. Whether the sheer presence or the extractive diffusion is the driving force cannot be finally judged from the present data. It might be part of future work.

The received data allow a determination of activation energies of the diffusion process via an Arrhenius procedure (s. Fig. 10). Results are displayed in Table 6. Differences between the single mineral oil/elastomer combinations seem to be only very subtle. However, a difference between diffusion of IRM 902 and IRM 903 is identifiable. And it can also be derived that elastomers with higher acrylonitrile content show a higher activation energy. The activation energy can be seen as a measure of the temperature influence on the velocity of diffusion processes. Higher activation energies are equivalent to a more pronounced temperature-induced acceleration.

Activation energies correlate to the resistivity of an elastomer against mineral oils: The higher the elastomer compatibility with a mineral oil, the higher is the temperature
Table 5 Diffusion coefficients for IRM 903 (left) and IRM 902 (right) in elastomers E18, E28 and E39 determined by iteration of Eq. (2)

\begin{tabular}{|c|c|c|c|c|c|c|c|c|c|}
\hline \multicolumn{5}{|l|}{ IRM 903} & \multicolumn{5}{|l|}{ IRM 902} \\
\hline \multirow[t]{2}{*}{ Elastomer } & \multicolumn{4}{|c|}{$\mathrm{D} / 10^{-6} \mathrm{~cm}^{2} \mathrm{~s}^{-1}$} & \multirow[t]{2}{*}{ Elastomer } & \multicolumn{4}{|c|}{$\mathrm{D} / 10^{-6} \mathrm{~cm}^{2} \mathrm{~s}^{-1}$} \\
\hline & $120^{\circ} \mathrm{C}$ & $100{ }^{\circ} \mathrm{C}$ & $80^{\circ} \mathrm{C}$ & $60^{\circ} \mathrm{C}$ & & $120^{\circ} \mathrm{C}$ & $100{ }^{\circ} \mathrm{C}$ & $80^{\circ} \mathrm{C}$ & $60^{\circ} \mathrm{C}$ \\
\hline E18 & 6.5 & 3.2 & 1.5 & 0.6 & E18 & 1.9 & 1.0 & 0.4 & 0.1 \\
\hline E28 & 5.8 & 3.1 & 1.1 & 0.3 & E28 & 1.2 & 0.6 & 0.2 & 0.1 \\
\hline E39 & 4.1 & 2.0 & 0.6 & 0.2 & E39 & 0.9 & 0.5 & 0.1 & n. $d$ \\
\hline
\end{tabular}



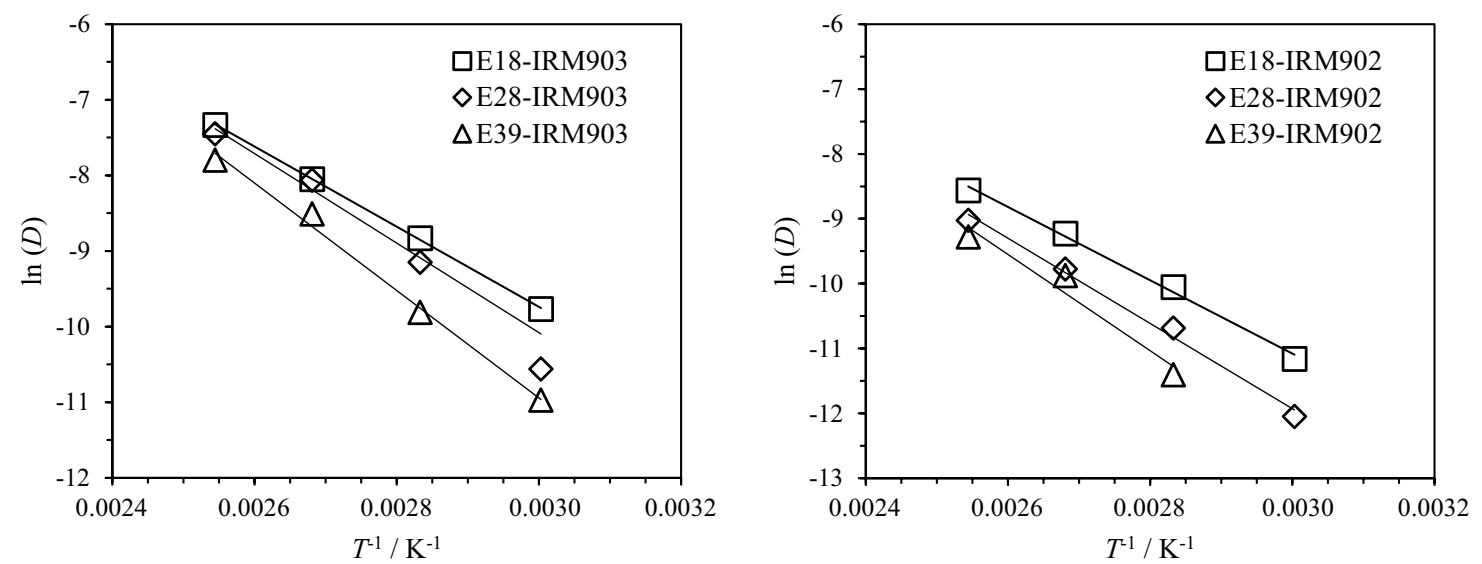

Fig. 10 Arrhenius plot for diffusion coefficients for IRM 903 (left) and IRM 902 (right)

Table 6 Activation energies of diffusion of mineral oils in elastomers determined from migration experiments

\begin{tabular}{lll}
\hline Elastomer & \multicolumn{2}{l}{$\mathrm{E}_{\mathrm{A}} / \mathrm{kJ} / \mathrm{mol}$} \\
\cline { 2 - 3 } & IRM903 & IRM902 \\
\hline E18 & 44.1 & 47.0 \\
E28 & 49.2 & 54.6 \\
E39 & 59.0 & 61.7 \\
\hline
\end{tabular}

influence. An explanation for this can be found in the compatibility itself. For a given oil / elastomer combination, it is logical, that the temperature influence is more pronounced for compatible elastomers, as the polymer chain mobility, which seems to be the rate-limiting step, is increased by temperature. From the point of view of the mineral oil, the effect is confirmed equal. IRM 902, which has a lower swelling potential, shows higher activation energies for all tested elastomers which is in good agreement with the sorption experiments. Beyond the observed trends, absolute numbers for activation energies of the two experimental setups are in very good accordance.
Although absolute numbers for diffusion coefficients vary by two orders of magnitude within these two types of experiment, trends within one series are in very good agreement. Depending on the analytical focus, the appropriate experimental setup can be selected. Sorption experiments focus on the overall oil uptake and enable general statements on the behavior of fluids and elastomers. Migration experiments, additionally, allow the generation of information on locally resolved effects.

One further very valuable advantage of the migration experiments is that the experimental setup allows a direct correlation of the chemical composition with mechanical properties. Figure 11 shows concentration profiles of adsorbed IRM 903 and residual elastomer plasticizer DEHP in relationship to the Shore A hardness in dependence on the penetration depth.

It can be seen that independent of the elastomer, type an extraction of DEHP occurs in a comparable extent. A significant loss of plasticizer approximately takes place in the first $12 \mathrm{~mm}$ of each specimen. The type of oil seems
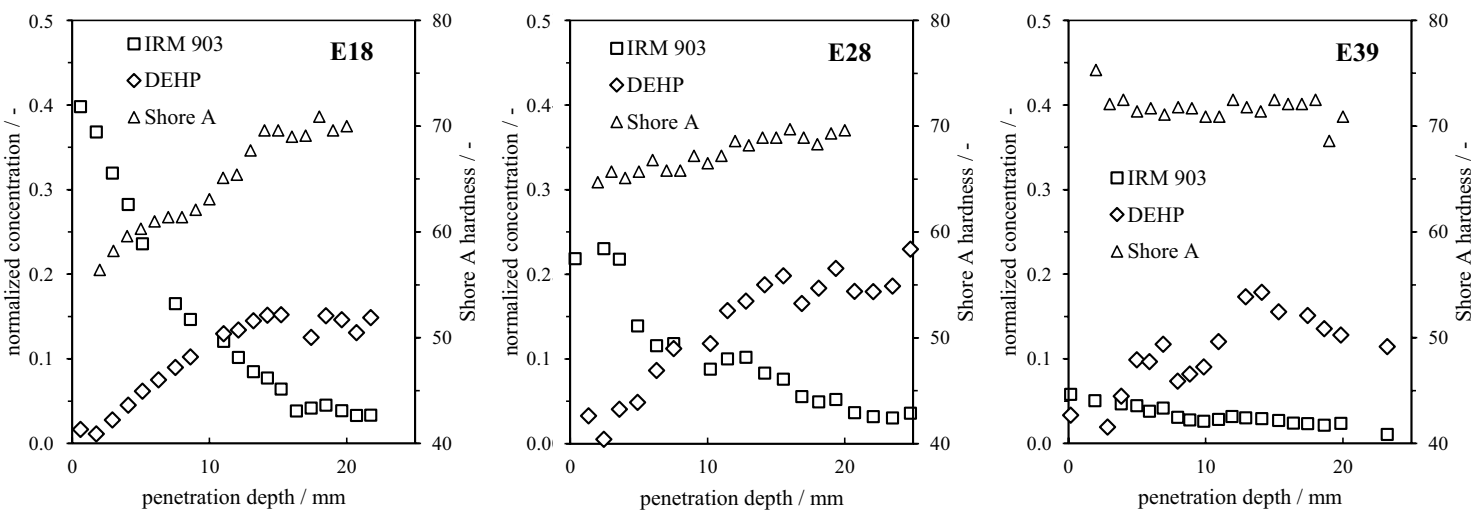

Fig. 11 Profiles of IRM 903 and DEHP concentrations and Shore A hardness of elastomers E18, E28 and E39 after 24 h in mineral oil (migration experiments) 
to have a minor effect. It is supposed that the very polar DEHP diffuses comparably fast in all tested elastomers under these experimental conditions. Storage of E39 in IRM 903 does not lead to significant changes of the material's hardness over the whole specimen. A negligible increase of hardness at a penetration depth of 0 certainly can be attributed to the complete loss of plasticizer with nearly no uptake of mineral oil. In contrary, adsorption of mineral oil, both IRM 902 and IRM 903, leads to a reduction of hardness, even when the plasticizer is completely extracted. This effect is more distinct in the case of IRM 903. Not only the higher amount of adsorbed oil, but also the oil type seems to affect this observation.

\section{Conclusions}

This work presents an experimental approach to quantify diffusion of mineral oils in NBR. Classical sorption experiments were performed to characterize diffusion processes of mineral oils in elastomers. Diffusion coefficients determined via gravimetrically evaluated sorption experiments allow a general assessment of the compatibility of elastomers and mineral oils. It was shown that diffusion coefficients are relatively small at lower temperatures and elastomers with high acrylonitrile contents. The reason for this is a reduced degree of attractive interactions. IRM 903, showing the highest aromatic fraction and the lowest boiling range, exhibits highest diffusion coefficients. With increasing sterical demand of the diffusing molecules and increasing viscosity, diffusion proceeds slower.

Activation energies of diffusion give a valuable tool to compare different systems of fluids and NBR elastomers regarding their compatibility. The temperature acceleration effect was shown to be more pronounced when interactions between solid and fluid are less intense, i.e., elastomers with high acrylonitrile contents show higher activation energies when in contact with the same mineral oil. Thus, the activation energy of diffusion can be considered as a very well quantifiable measure for the compatibility. Whether this conclusion is appropriate for other elastomer types than NBR, should be part of future works.

To describe transport phenomena locally resolved, diffusion experiments with elastomer specimens dipped in a very low amount of mineral oil were performed. This procedure allows a determination of the penetration depth of mineral oils. And it can also give valuable information on the chemical constitution of elastomers. This procedure additionally offers the possibility to investigate the material's hardness in dependence on the penetration depth. This description of the diffusion progress in combination with mechanical properties helps to understand diffusion processes in larger elastomer components, which suffer from heterogeneous property changes after contact to mineral oils. Activation energies of diffusion determined by migration experiments follow the same trends compared to sorption experiments.

Absolute values of diffusion coefficients determined with the two presented methods are of limited comparability because of substantial differences in the experimental procedure. Oil concentrations are very high for sorption experiments, which might lead to obstructions in the diffusion. On the other hand, only little oil concentrations in the migration experiments allow unhindered movement of the mineral oils. Although differences in the absolute numbers occur, activation energies of diffusion are very similar and follow equal trends and, therefore, give a possibility to evaluate the complex interplay between material's properties on the one hand and swelling potential on the other hand. Consequently, activation energies of diffusion are assumed a suitable and analytically easy accessible measure for the compatibility of elastomers and fluids.

Acknowledgements The authors want to thank Nadine Weber and Johannes Bibinger for their experimental support. Furthermore, Jens Ortner is acknowledged for fruitful scientific discussions.

\section{Compliance with ethical standards}

Conflict of interest On behalf of all authors, the corresponding author states that there is no conflict of interest.

Open Access This article is licensed under a Creative Commons Attribution 4.0 International License, which permits use, sharing, adaptation, distribution and reproduction in any medium or format, as long as you give appropriate credit to the original author(s) and the source, provide a link to the Creative Commons licence, and indicate if changes were made. The images or other third party material in this article are included in the article's Creative Commons licence, unless indicated otherwise in a credit line to the material. If material is not included in the article's Creative Commons licence and your intended use is not permitted by statutory regulation or exceeds the permitted use, you will need to obtain permission directly from the copyright holder. To view a copy of this licence, visit http://creativecommons.org/licenses/by/4.0/.

\section{References}

1. Röthemeyer F, Sommer F (2006) Kautschuk technologie-werkstoffe-verarbeitung—produkte, 2nd edn. Carl Hanser Verlag, Munich

2. Magryta J, Dẹbek C, Dębek D (2006) J Appl Polym Sci 99:2010

3. Förster T (2017). In: Öchsner A, Altenbach H (eds) Prop. Charact. Mod. Mater. Adv. Struct. Mater. Springer, Singapore

4. Haseeb ASMA, Jun TS, Fazal MA, Masjuki HH (2011) Energy 36:1814

5. Uedelhoven W (1990) J Synthetic Lubric 7:105

6. Neppel A (1986) Rubber Chem Technol 59:46

7. Ehrenstein GW, Pongratz S (2013) Resistance and stability of polymers. Hanser Pubishers, Munich

8. Haseeb ASMA, Masjuki HH, Siang CT, Fazal MA (2010) Energy $35: 2356$ 
9. Haseeb ASMA, Fazal MA, Jahirul MI, Masjuki HH (2011) Fuel 90:922

10. E. Konrad, E. Tschunkur Patent DE658172, 07 July 1930

11. Baumann W, Ismeier M (1998) Kautschuk und gummi daten und fakten zum umweltschutz, vol 1. Springer, Berlin, Heidelberg

12. Domininghaus H (2005) Die Kunststoffe und ihre eigenschaften, 6th edn. Springer, Berlin, Heidelberg, New York

13. Schatt W, Horch H (1996) Werkstoffwissenschaft, 8th edn. Deutscher Verlag für Grundstoffindustrie, Stuttgart

14. Asfour AA, Saleem M, De Kee D, Harrison BH (1989) J Appl Polym Sci 38:1503

15. Seehra MS, Yalamanchi M, Singh V (2012) Polym Test 31:564

16. Scheuermann SS, Forster S, Eibl S (2017) Energy Fuels 31:2934

17. DeWitt MJ, Corporan E, Graham J, Minus D (2008) Energy Fuels 22:2411

18. DIN ISO 1817 (2005) Rubber, vulcanized - Determination of the effect of liquids. https://doi.org/10.31030/2561578
19. Bellili A, David N, Vandame B, Wang Q, Goutille Y, Richaud E (2012) Polym Test 31:236

20. Aminabhavi TM, Phayde HTS, Ortego JD, Vergnaud JM (1996) Polymer (Guildf) 37:1677

21. George S, Varughese KT, Thomas S (2000) Polymer (Guildf) 40:579

22. Henrici-Olivé G, Olivé S (1979) Adv Polym Sci 32:123

23. Mathai AE, Thomas S, Richaud E (1996) J Macromol Sci 35:229

24. Fouchet B (2008) J Appl Polym Sci 111:2886

25. Hauffe K, Seyferth C (1966) Reaktionen in und an festen Stoffen, 2nd edn. Springer-Verlag, Berlin, Heidelberg, New York

Publisher's Note Springer Nature remains neutral with regard to jurisdictional claims in published maps and institutional affiliations. 